\title{
Poiseuille geometry shear flow apparatus for small-angle scattering experiments
}

\author{
Veronica M. Cloke, ${ }^{\text {a) }}$ Julia S. Higgins, C. Lin Phoon, and Stephen M. Richardson
}

Department of Chemical Engineering, Imperial College, London SW7 2BY, United Kingdom

Stephen M. King, Robert Done, and Trevor E. Cooper

ISIS Spallation Neutron Source, Rutherford Appleton Laboratory, Chilton, Didcot OX11 OQX, United Kingdom

(Received 9 November 1995; accepted for publication 9 May 1996)

\begin{abstract}
A new apparatus to investigate the structure of fluids under Poiseuille shear flow using small-angle neutron or light scattering techniques is described. Important features of the design include low sample volumes, area average shear rates of up to $5000 \mathrm{~s}^{-1}$, accurate temperature control over the range of $10-125^{\circ} \mathrm{C}$, and the ability to study the development of flow-induced alignment phenomena. Small-angle neutron scattering data are presented for two example systems: the well-characterized surfactant system $\mathrm{C}_{16} \mathrm{E}_{6} / \mathrm{D}_{2} \mathrm{O}$, used to contrast the effects of Poiseuille and Couette flow, and the block copolymer Synperonic P-85/ $\mathrm{D}_{2} \mathrm{O}$ system. (C) 1996 American Institute of Physics. [S0034-6748(96)04708-9]
\end{abstract}

\section{INTRODUCTION}

\section{A. Background}

The long-range correlations and degree of molecular order in a flowing fluid can be rather different from those present in a fluid at rest. This simple fact has enormous significance in the industrial arena where the behavior and properties of a fluid under flow, its rheology, can affect or even dictate the conditions of the transporting or processing of a product.

The combination of shear flow and small-angle neutron scattering (SANS) or small-angle x-ray scattering (SAXS) has been widely used for the study of colloidal systems such as dispersions of cylindrical or rodlike surfactant micelles. ${ }^{1}$ This is because, by aligning the micelles in a shear field, the orientational averaging effect normally conferred on the static scattering pattern by, among other things, the Brownian motion of the micelles, is removed. Analysis of the resulting anisotropic scattering pattern can then provide estimates of the micellar contour length, cross-sectional radius, flexibility (persistence length), and polydispersity, and also allows studies of hindered rotation. Other workers have investigated the behavior of concentrated dispersions of polymer latex particles, ${ }^{2}$ clays,${ }^{3}$ and polymer solutions ${ }^{4}$ under shear. There has also been growing interest in shear-induced structural changes in systems such as liquid crystalline surfactant phases and ordered diblock copolymer melts. ${ }^{5}$ Very recently, shear flow has been combined with the technique of neutron reflectometry, enabling thin flowing films and boundary layer effects to be investigated, and with an x-ray Surface Forces apparatus. ${ }^{6}$

Although many workers have utilized shear flow apparatus of the Couette and Searle (concentric cylinder ${ }^{7}$ ) or twin disk $^{8}$ design, far fewer workers have utilized Poiseuille shear flow. ${ }^{2,5,9}$ In the main this seems to be due to the larger sample volume necessary, although there are other practical

\footnotetext{
a) Author to whom all correspondence should be addressed.
}

and theoretical considerations that space prevents us from discussing here. Such apparatus does, however, have applications in the study of industrial systems. ${ }^{10}$

\section{B. Poiseuille flow}

Poiseuille flow is the laminar flow $(\operatorname{Re}<2000)$ of a fluid in a pipe under a constant pressure gradient. Irrespective of the fluid type, in Poiseuille flow the velocity at the pipe wall is essentially zero, increasing to a maximum at the center of the pipe. The shear rates in the pipe mirror this. If Newtonian, the fluid adopts a parabolic velocity profile. Geometrically similar profiles are generated when a fluid passes between two static parallel plates and this modified geometry lends itself more readily to experimental investigations.

To encompass the range of shear rates present between the plates, the area-average shear rate, ${ }^{11}$

$$
\dot{\gamma}_{\mathrm{av}}=\frac{2 Q}{w h^{2}} \frac{(m+2)}{(m+1)},
$$

has been used throughout this article, where $Q$ is the volumetric flow rate, $w$ is the width of the plates, $h$ is the separation of the plates, and $m$ is the dimensionless shear rate exponent in the power law equation

$$
\mu=\mu_{0} \dot{\gamma}^{[(1 / m)-1]}
$$

relating the viscosity $\mu$ and consistency $\mu_{0}$ of the polymer. For Newtonian fluids $m=1$. For non-Newtonian fluids $m$ must be determined from rheological measurements.

For a fluid flowing between two parallel plates, the distance after which laminar flow is fully developed; the entry length $L_{e}$ is given by ${ }^{12}$

$$
\frac{2 L_{e}}{h}=\frac{c \rho Q}{w \mu}=c \operatorname{Re},
$$

where $c$ is a dimensionless experimental constant ${ }^{12,13}$ of the order $0.03-0.1$ and $\rho$ is the density of the fluid.

Equation (3) highlights an advantage of Poiseuille shear flow, namely, that it permits the study of the evolution of 


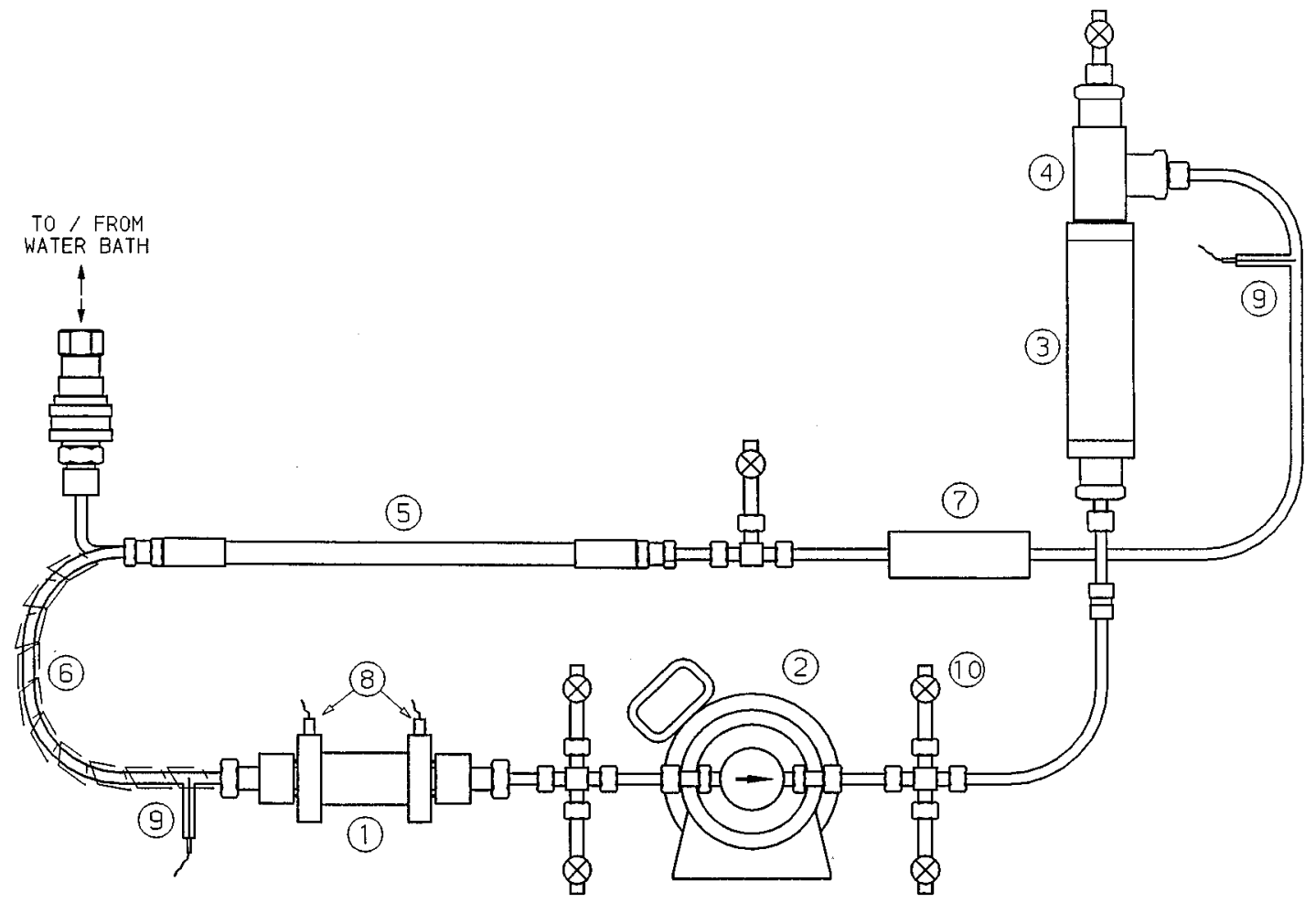

FIG. 1. Schematic diagram of the Poiseuille shear flow apparatus. The numbered components are described in the text.

flow-induced phenomena in a complementary, and arguably more practical (from the perspective of a scattering measurement), manner than is possible with Couette shear flow. In the Poiseuille apparatus of the parallel plate geometry, the fluid is subject to a complex flow as it expands from the confines of the inlet pipe. This serves to scramble or randomize any structure in the fluid. However, further along the channel the flow becomes better defined and alignment more pronounced. This behavior is illustrated in Sec. III B.

\section{DESCRIPTION OF SHEAR FLOW APPARATUS}

A schematic of the Poiseuille flow cell apparatus is shown in Fig. 1. The apparatus is a closed recirculating system comprised of a quartz flow cell (1) (Optiglass Ltd.), an electrically driven, magnetically coupled, three-gear pump (2) (Micropump ${ }^{\circledR}$ series D, CP Instrument Company Ltd.) for pulseless flow, and a glass in-line flowmeter (3) (FL-214 rotameter, Omega Engineering Ltd.). These are all interconnected by polytetrafluoroethylene (PTFE) fittings and lagged $1 / 4$ in. $(6.35 \mathrm{~mm})$ by o.d. PTFE tubing. PTFE is used for its chemical inertness and poor thermal conductivity. The pump gears are made from Ryton ${ }^{\circledR}$ (polyphenylene sulphide), an equally inert material, and are enclosed in a stainless steel housing. The layout of the components has been carefully chosen so that wherever possible the sample follows gentle curves as it circulates; this design prevents complex or even turbulent flow occurring at $90^{\circ}$ bends.

The fluid reservoir (4) allows air to be vented from the solution. The cell can be loaded via any one of six vents (10) using a syringe. The vents have been positioned in such a way to allow easy venting of the system, it being important to minimize the amount of air trapped in the apparatus. It is relatively easy to dismantle the apparatus for cleaning.

Temperature control is facilitated by three short sections of stainless steel tubing in the circuit. One of these passes through a heat exchanger (5) connected to a thermostated circulating fluid bath, another is wrapped in heating tape (6), and the third is surrounded by four cartridge heaters in a brass block (7). These sections of tubing have been placed so that the solution is heated as evenly as possible as it circulates. Another four cartridge heaters are mounted in stainless steel blocks at either end of the quartz cell (8). These blocks also serve as a compression fitting to join the tubing to the quartz cell. For temperature measurement the apparatus is fitted with two $K$-type thermocouples (9). The position of the thermocouples in a small $\mathrm{T}$ section may affect the flow pattern through the tubing, but the effect is not significant enough to disturb the region of interest in the quartz cell. One thermocouple is positioned in front of the entrance to the quartz cell and the other approximately halfway around the circuit. The measured temperature difference across the circuit is generally no more than $\pm 2{ }^{\circ} \mathrm{C}$, and can be improved to $\pm 1{ }^{\circ} \mathrm{C}$ at higher flow rates. The operational temperature range of this apparatus is determined by the efficiency of the heat exchanger for temperatures below ambient and by the specification of the PTFE fittings at higher temperatures. We have achieved a range of $10-125^{\circ} \mathrm{C}$. However, since circulation is important to achieving the desired temperature and preventing the formation of hot and cold spots, zero-shear measurements are only realistic at room temperature.

Inside the quartz flow cell, detailed in Fig. 2, the fluid 


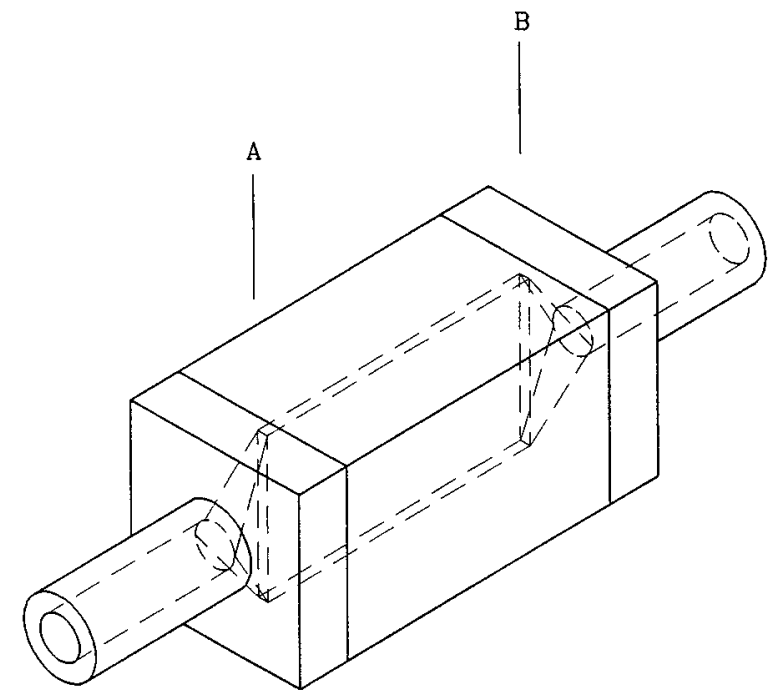

FIG. 2. Schematic diagram of the quartz flow cell. Item (1) in Fig. 1. The labels are explained in Sec. III B.

passes through a rectangular channel $1 \mathrm{~mm}$ in pathlength and $20 \times 50 \mathrm{~mm}$ in elevation. At the two ends of the channel the quartz has been carefully machined so that it tapers to the internal diameter of the tubing $(5 / 32 \mathrm{in} ., 3.96 \mathrm{~mm})$ in such a way that backeddies or vortices, which would otherwise form at sharp corners, are essentially eliminated. This was checked visually with a colored solution. The quartz cell has been designed so that, if required, it can be rotated $90^{\circ}$ around the flow direction.

For shear rate determination it is important to know $Q$ accurately, particularly if the viscosity of the sample changes with temperature. The volume of the apparatus is approximately $80 \mathrm{~cm}^{3}$ with the flowmeter connected into the circuit and approximately $35 \mathrm{~cm}^{3}$ without it. The pump is rated to $3000 \mathrm{rpm}$ which is sufficient for a flow rate of approximately $30 \mathrm{~cm}^{3} \mathrm{~s}^{-1}\left(1.8 / \mathrm{min}^{-1}\right)$ to be attained if the apparatus is filled with water. The range of area-average shear rate that is accessible with this apparatus is therefore $\sim 100-5000 \mathrm{~s}^{-1}$.

\section{EXPERIMENTAL RESULTS}

The surfactant hexaethylene glycol monohexadecyl ether (also called 6 cetyl ether or $\mathrm{C}_{16} \mathrm{E}_{6}$ ) was obtained from Sigma Chemicals, UK, and was used as supplied.

A sample of the low-molecular weight poly(oxyethylene)-poly(oxypropylene)-poly(oxyethylene) triblock copolymer Synperonic P-85 was obtained from ICI Surfactants, Middlesbrough, UK. Since the commercial material is reported to contain small amounts of the diblock and other impurities it was purified before use. ${ }^{14}$ The polydispersity $\left(\mathrm{M}_{w} / \mathrm{M}_{n}\right)$ of the copolymer after purification was $\leqslant 1.3$.

Deuterium oxide, isotopic purity $99.9+$ at. \% D, was obtained from Fluorochem Ltd., UK, and was used as supplied.

SANS measurements were performed on the LOQ diffractometer ${ }^{15}$ at the ISIS Spallation Neutron Source, Oxfordshire, UK. ${ }^{16}$ This is a fixed-geometry, time-of-flight, instrument equipped with a $64 \times 64 \mathrm{~cm}$ position-sensitive de- tector. Neutrons with wavelengths between 0.2 and $1.0 \mathrm{~nm}$ are combined to provide a simultaneous $q$ range of approximately $0.06-2.2 \mathrm{~nm}^{-1}$ where

$$
q=\left(\frac{4 \pi}{\lambda}\right) \sin \left(\frac{\theta}{2}\right)
$$

is the modulus of the scattering vector, the resultant between the incident and scattered wave vectors, while $\lambda$ is the neutron wavelength, and $\theta$ is the scattering angle. The effective wavelength resolution was $\Delta \lambda / \lambda \approx 5 \%$. The incident neutron beam was collimated to a $10 \mathrm{~mm}$ diameter at the sample.

All scattering data were normalized for sample transmission and incident wavelength distribution, background corrected using a flow cell filled with $\mathrm{D}_{2} \mathrm{O}$ (this also removes the inherent instrumental background from vacuum windows, etc.), and corrected for the linearity and efficiency of the detector response using an instrument-specific software package. ${ }^{17}$ The data were converted to absolute units by scaling them to the scattering from a well-characterized partially deuterated polystyrene blend calibration sample. ${ }^{18}$

\section{A. Comparison of Poiseuille and Couette flows}

For this comparison we present SANS data from a $1.1 \%$ w/w solution of $\mathrm{C}_{16} \mathrm{E}_{6}$ in $\mathrm{D}_{2} \mathrm{O}$ at $30{ }^{\circ} \mathrm{C}$. This is a wellcharacterized micellar system. ${ }^{19}$ In a zero-shear environment the surfactant self-assembles into cylindrical micelles approximately $6 \mathrm{~nm}$ in radius and some $300 \mathrm{~nm}$ in length but, when subjected to a shear flow field, the long axis of the micelles has been shown to align around the flow direction. This generates an anisotropic scattering pattern that is perpendicular to the anisotropy of the particles.

SANS data were collected from this system in both the Poiseuille flow apparatus and in the Couette flow apparatus of Cummins et al. ${ }^{7}$ In the Couette apparatus a uniform shear rate of $5000 \mathrm{~s}^{-1}$ was maintained, while in the Poiseuille apparatus the measurements were made at an area-average shear rate of $5000 \mathrm{~s}^{-1}$.

As can be seen from the corrected intensity contour plots in Figs. 3(a) and 3(b), both types of flow induce anisotropy in the scattering pattern. The scattering from the micelles under Poiseuille flow is, however, markedly less anisotropic than that generated by Couette flow. Calculation of the anisotropy ratios (the ratio of the scattering perpendicular and parallel to the flow direction averaged over a range of $q$ ) reveals that for this system the alignment achieved under Couette flow is approximately three times greater than that under Poiseuille flow. This is because in Poiseuille flow the rodlike micelles are simultaneously subjected to a range of shear rates. This is not the case in Couette flow. Consequently, towards the center of the Poiseuille flow cell, where the shear rate tends toward zero, the conditions for alignment are not as favorable. Micelles in this central region of the cell are therefore subjected to a lower average shear rate than those at the cell walls. The resulting scattering pattern is thus a convolution of signals from micelles in differing degrees of alignment. 


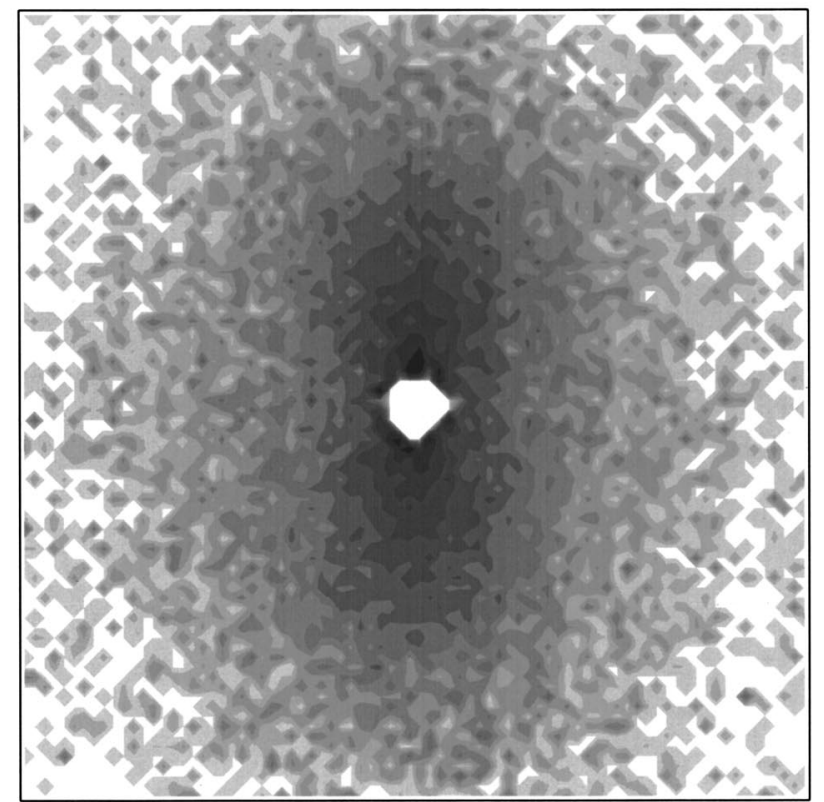

(a)

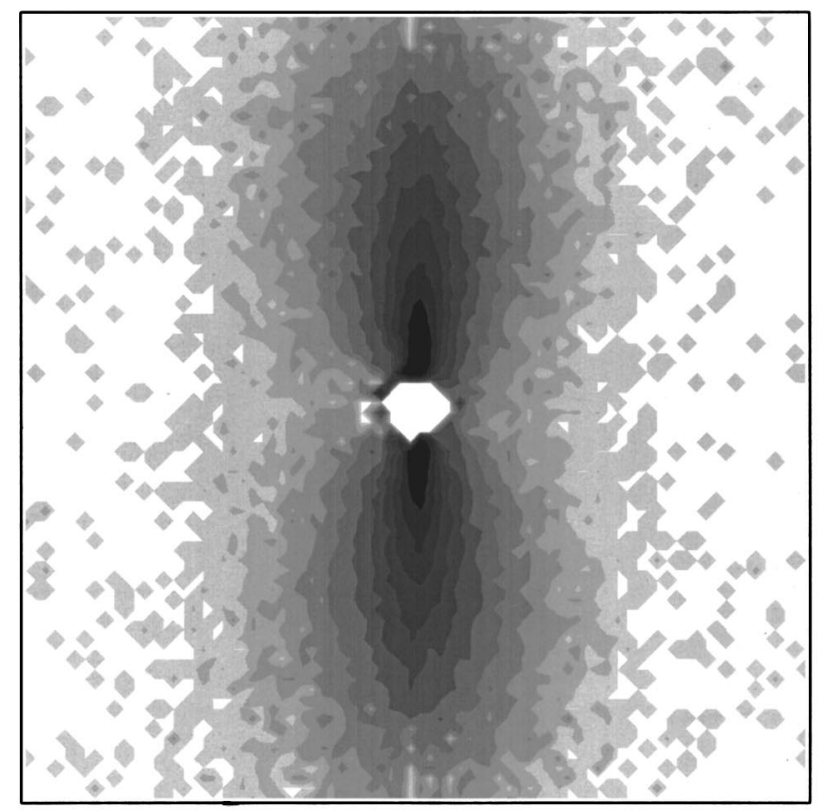

(b)

FIG. 3. Corrected intensity contour plots comparing the effect of two different types of shear flow on the same system. (a) Poiseuille shear flow (anisotropy ratio 2.3), (b) Couette shear flow (anisotropy ratio 7.7). 1.1\% w/w $\mathrm{C}_{16} \mathrm{E}_{6}$ in $\mathrm{D}_{2} \mathrm{O}$ at a shear rate of $5000 \mathrm{~s}^{-1}$ and temperature of $30{ }^{\circ} \mathrm{C}$. The horizontal and vertical axes correspond to the components of the scattering vector, $q$, parallel and perpendicular to the direction of flow, respectively. Both axes cover the range $-0.8 \leqslant q\left(\mathrm{~nm}^{-1}\right) \leqslant+0.8$ and the contour levels are the same in each plot.

\section{B. Evolution of alignment}

For these measurements a $1.0 \% \mathrm{w} / \mathrm{w}$ solution of Synperonic $\mathrm{P}-85$ in $\mathrm{D}_{2} \mathrm{O}$ was used. Above the critical micellization temperature, about $30{ }^{\circ} \mathrm{C}$, the block copolymer molecules aggregate into roughly spherical micelles. Above approximately $63{ }^{\circ} \mathrm{C}$ these elongate into rodlike micelles. ${ }^{20}$ Like the $\mathrm{C}_{16} \mathrm{E}_{6}$ micelles discussed above, these rodlike copolymer micelles also become aligned in a shear field.

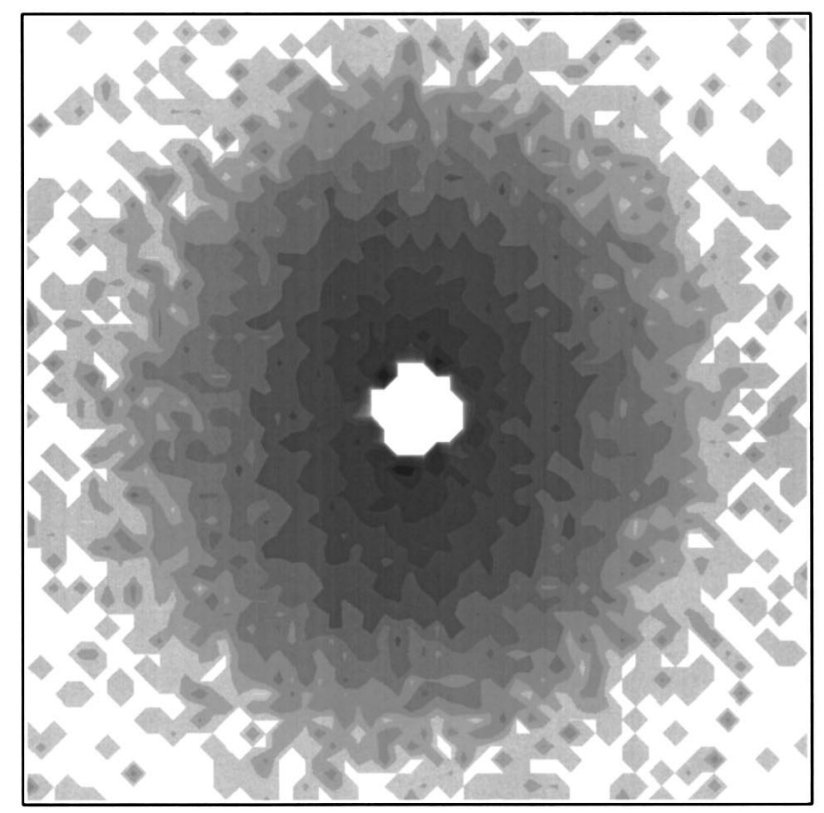

(a)

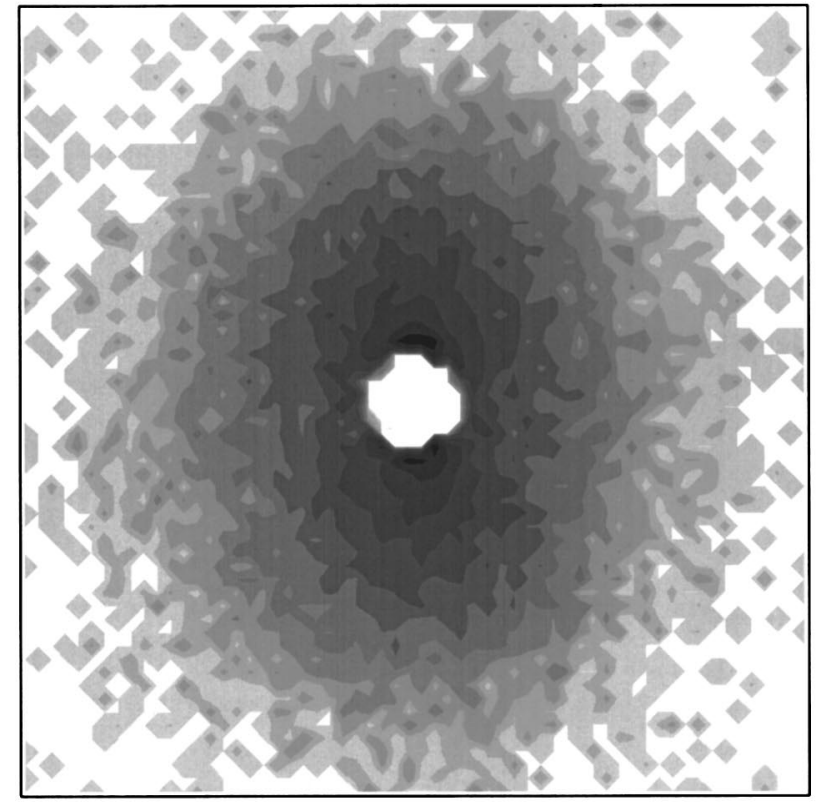

(b)

FIG. 4. Corrected intensity contour plots comparing the effect of Poiseuille shear flow at two different positions along the flow cell on the same system. (a) $10 \mathrm{~mm}$ from the entrance (anisotropy ratio 1.6), (b) $35 \mathrm{~mm}$ from the entrance (anisotropy ratio 2.7). 1.0\% w/w Synperonic P-85 in $\mathrm{D}_{2} \mathrm{O}$ at a temperature of $76^{\circ} \mathrm{C}$. The horizontal and vertical axes correspond to the components of the scattering vector, $q$, parallel and perpendicular to the direction of flow, respectively. Both axes cover the range $-0.6 \leqslant q$ $\left(\mathrm{nm}^{-1}\right) \leqslant+0.6$ and the contour levels are the same in each plot.

For this system the entrance length, $L_{e}$ [see Eq. (3)] is calculated to be $25 \mathrm{~mm}$, that is, $25 \mathrm{~mm}$ downstream of position A in Fig. 2 the system is in a fully developed laminar flow. Thus, by moving the position of the center of the neutron beam between A and B it is possible to study the developing anisotropy in the scattering (developing alignment).

Measurements were made with the neutron beam initially $10 \mathrm{~mm}$ downstream from A, within the region of developing flow, and in the fully developed region $35 \mathrm{~mm}$ 


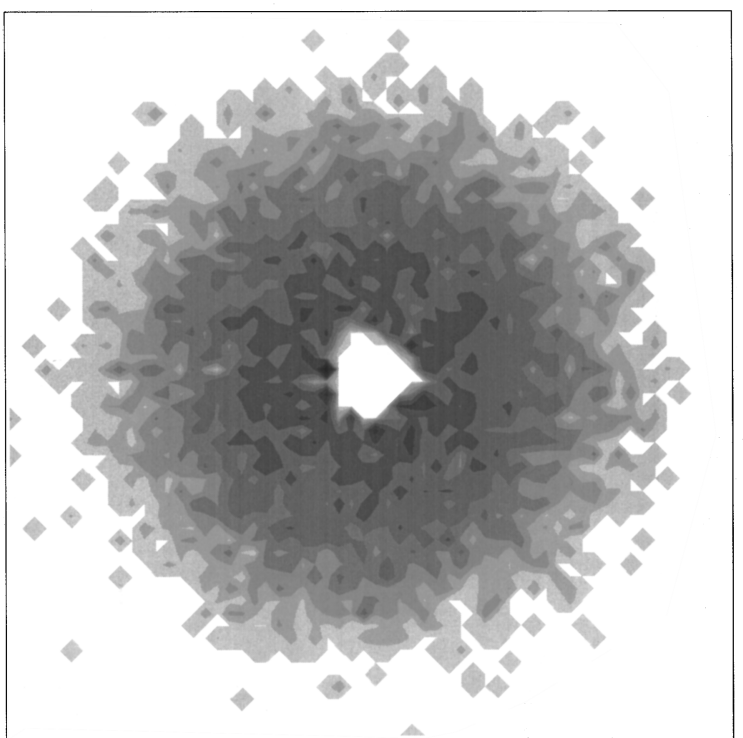

(a)

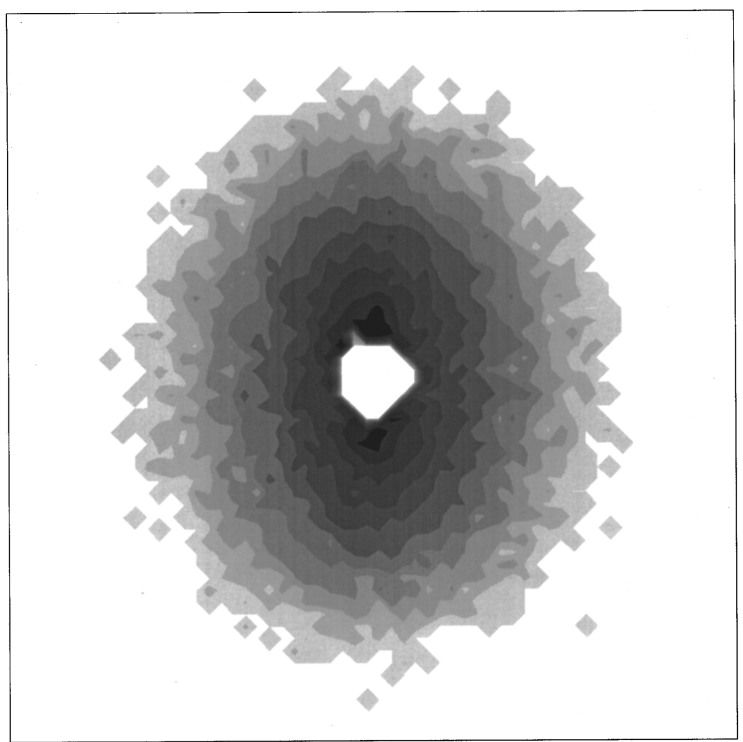

(b)

downstream. Evidence of the developing alignment of the micelles comes from the distinct change in anisotropy ratio, from 1.6 in the developing region to 2.7 when the flow is fully developed [Figs. 4(a) and 4(b)]. This is despite the fact that the relatively large diameter of the incident beam must result in a significant degree of orientational averaging (particularly in the developing region) and in the effects of polydispersity in molecular weight (which result in a broader distribution of rod lengths than in the $\mathrm{C}_{16} \mathrm{E}_{6}$ system above). We propose to investigate these effects in more detail in a future experiment using narrow slit collimation. This type of study is difficult to accomplish in a Couette shear cell except when it is operated in an oscillatory mode; however this can in itself introduce other experimental difficulties.

\section{Effect of shear and temperature on P-85 in solution}

The Synperonic family of copolymers is used in many different industrial formulations, and so their behavior under

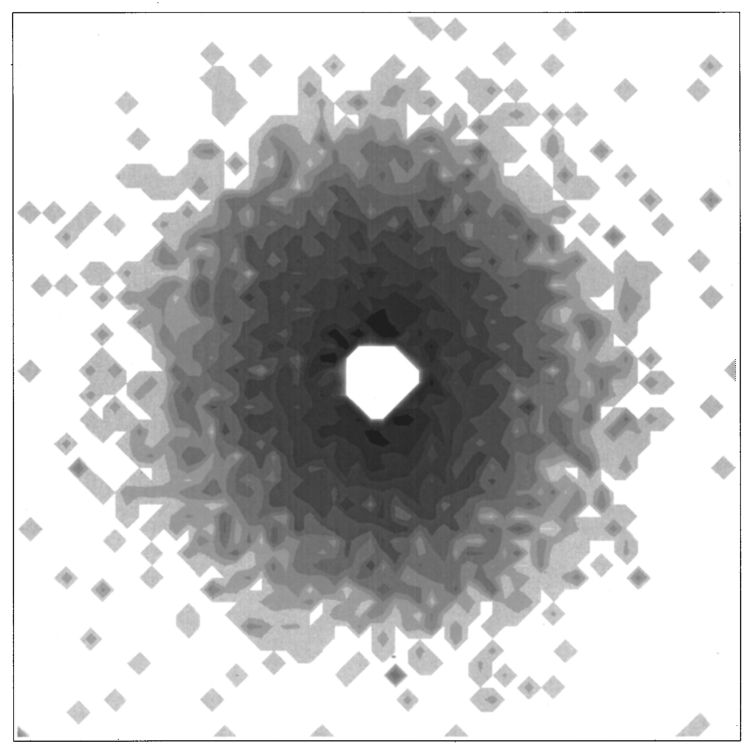

(c)

FIG. 5. Corrected intensity contour plots comparing the effect of Poiseuille shear flow at different temperatures and shear rates on the same system. (a) $61{ }^{\circ} \mathrm{C}$ and $600 \mathrm{~s}^{-1}$, (b) $74^{\circ} \mathrm{C}$ and $600 \mathrm{~s}^{-1}$, (c) $75^{\circ} \mathrm{C}$ and $1550 \mathrm{~s}^{-1} .1 .0 \%$ w/w Synperonic P-85 in $\mathrm{D}_{2} \mathrm{O}$. The horizontal and vertical axes correspond to the components of the scattering vector, $q$, parallel and perpendicular to the direction of flow, respectively. Both axes cover the range $-0.6 \leqslant q$ $\left(\mathrm{nm}^{-1}\right) \leqslant+0.6$ and the contour levels are the same in each plot.

likely processing conditions is of more than just academic interest. Another reason for our interest in the $\mathrm{P}-85 / \mathrm{D}_{2} \mathrm{O}$ system is that the transition from spherical to rodlike micelles was only discovered comparatively recently ${ }^{21}$ and all (light, $\mathrm{x}$-ray and neutron) scattering data on this system at low concentrations has, to date, been obtained in the absence of shear. Undoubtedly one of the reasons for this is that much of the available Couette and Searle shear flow apparatus for use with $\mathrm{x}$ rays and neutrons is limited to a maximum temperature of around $50{ }^{\circ} \mathrm{C}$ by the materials or methods of construction.

With this in mind we have conducted a detailed SANS study of this system between the sphere-to-rod transition temperature and the cloud point $\left(\sim 82{ }^{\circ} \mathrm{C}\right)$. Our preliminary findings will be reported in detail elsewhere, ${ }^{20}$ but we show here some representative data that illustrate how the system responds to changes in temperature and shear.

Figure 5(a) shows the SANS from a $1 \%$ w/w solution of 
P-85 in $\mathrm{D}_{2} \mathrm{O}$ in the Poiseuille shear flow apparatus at a constant average shear rate of $600 \mathrm{~s}^{-1}$ and at a temperature of $61{ }^{\circ} \mathrm{C}$, that is, just below the sphere-to-rod transition temperature. The scattering is comparatively weak and isotropic, showing that there is no alignment of the micelles. At this temperature the micelles are, broadly speaking, spherical. In Fig. 5(b) the temperature has been raised to $74{ }^{\circ} \mathrm{C}$, approximately $10{ }^{\circ} \mathrm{C}$ above the transition temperature. The scattering pattern is now elongated in the direction perpendicular to the fluid flow as would be expected from micelles aligning with the flow direction. Initial analysis of the data indicates that at this temperature the micelles have a cross-sectional radius of about $5 \mathrm{~nm}$ and a length of $60-70 \mathrm{~nm}$.

Figure 5(c) shows the scattering at $75{ }^{\circ} \mathrm{C}$ and $1550 \mathrm{~s}^{-1}$ (which is still within the laminar flow regime). By 2500 $\mathrm{s}^{-1}$ the scattering pattern is almost as isotropic as it is under zero-shear conditions, although at this shear rate the Reynolds number is between the upper limit for laminar flow and the lower limit for turbulent flow.

\section{ACKNOWLEDGMENTS}

The authors would like to thank the Engineering and Physical Sciences Research Council and ISIS for providing the materials and neutron beam time that have made this work possible. They would also like to express their gratitude to Richard Heenan, Jeff Penfold, and Ed Staples for their support and encouragement, and to all those members of the ISIS Project Engineering, Sample Environment, and Operations groups who have assisted them in one way or another over the years. One author (V.M.C.) would like to thank Shell Research for the award of a postgraduate studentship. The authors acknowledge ICI Surfactants for donating the Synperonic P-85 and thank Clive Washington for purifying it.

${ }^{1}$ P. Schurtenberger, L. J. Magid, J. Penfold, and R. K. Heenan, Langmuir 6, 1800 (1990); J. Penfold, E. Staples, and P. G. Cummins, Adv. Coll. Int. Sci. 34, 451 (1991), and references contained therein; V. Schmitt, F. Schosseler, and F. Lequeux, Europhys. Lett. 30, 31 (1995); B. Sjöberg, J. Appl. Crystallogr. 13, 154 (1980).

${ }^{2}$ P. Lindner, I. Markovic, R. C. Oberthür, R. H. Ottewill, and A. R. Rennie, Progr. Coll. Polym. Sci. 76, 47 (1988); S. Ashdown, I. Markovic, R. H. Ottewill, P. Lindner, R. C. Oberthür, and A. R. Rennie, Langmuir 6, 303 (1990); H. M. Laun, R. Bung, S. Hess, W. Loose, O. Hess, K. Hahn, E. Hädicke, R. Hingmann, F. Schmidt, and P. Lindner, J. Rheol. 36, 743 (1992).

${ }^{3}$ J. D. F. Ramsay and P. Lindner, J. Chem. Soc. Faraday Trans. 89, 4207 (1993); H. J. M. Hanley, G. C. Straty, and F. Tsvetkov, Langmuir 10, 3362 (1994).

${ }^{4}$ P. Lindner and R. C. Oberthür, Coll. Polym. Sci. 263, 443 (1985); P. Lindner and R. C. Oberthür, ibid. 266, 886 (1988).
${ }^{5}$ O. Diat, D. Roux, and F. Nallet, J. Phys. IV (Paris), 3, 193 (1993); J. F. Berret, D. C. Roux, G. Porte, and P. Lindner, Europhys. Lett. 25, 521 (1994); O. Diat and D. Roux, Langmuir 11, 1392 (1995); O. Diat, D. Roux, and F. Nallet, Phys. Rev. E 51, 3296 (1995); C. R. Safinya, E. B. Sirota, R. Plano, and R. F. Bruinsma, J. Phys. Cond. Matter 2, 365 (1990); C. R. Safinya, E. B. Sirota, and R. J. Plano, Phys. Rev. Lett. 66, 1986 (1991); J. T. Mang, S. Kumar, and B. Hammouda, Europhys. Lett. 28, 489 (1994); K. A. Koppi, M. Tirrell, F. S. Bates, K. Almdal, and R. H. Colby, J. Phys. II (Paris) 2, 1941 (1992); N. P. Balsara, B. Hammouda, P. K. Kesani, S. V. Jonnalagadda, and G. C. Straty, Macromolecules 27, 2566 (1994); M. Goulinan and S. T. Milner, Phys. Rev. Lett. 74, 1775 (1995); Y. Zhang, U. Wiesner, and H. W. Spiess, Macromolecules 28, 778 (1995).

${ }^{6}$ S. M. Baker, G. Smith, R. Pynn, P. Butler, J. Hayter, W. Hamilton, and L. Magid, Rev. Sci. Instrum. 65, 412 (1994); W. A. Hamilton, P. D. Butler, S. M. Baker, G. S. Smith, J. B. Hayter, L. J. Magid, and R. Pynn, Phys. Rev. Lett. 72, 2219 (1994); S. H. J. Idziak, I. Koltover, K. S. Liang, J. N. Israelachvili, and C. R. Safinya, 12th Symposium on Thermophysical Properties, 19-24 June 1994, Boulder, CO.

${ }^{7}$ P. Lindner and R. C. Oberthür, Rev. Phys. Appl. 19, 759 (1984); J. B. Hayter and J. Penfold, J. Phys. Chem. 88, 4589 (1984); G. C. Straty, J. Res. Nat. Inst. Stand. Technol. 94, 259 (1989); P. G. Cummins, E. Staples, B. Millen, and J. Penfold, Meas. Sci. Technol. 1, 179 (1990); A. I. Nakatani, H. Kim, and C. C. Han, J. Res. Nat. Inst. Stand. Technol. 95, 7 (1990); R. J. Plano, C. R. Safinya, E. B. Sirota, and L. J. Wenzel, Rev. Sci. Instrum. 64, 1309 (1993); A. Link and J. Springer, Macromolecules 26, 464 (1993).

${ }^{8}$ J. Kalus, G. Neubauer, and U. Schmelzer, Rev. Sci. Instrum. 61, 3384 (1990).

${ }^{9}$ P. Lindner, Physica A 174, 74 (1991); H. W. Bewersdorff, J. Dohmann, J. Langowski, P. Lindner, A. Maack, R. Oberthür, and H. Thiel, Physica B 156/157, 508 (1989).

${ }^{10}$ C. L. Phoon, Ph.D. thesis, Imperial College, University of London, London, 1992.

${ }^{11}$ V. M. Cloke, Ph.D. thesis, Imperial College, University of London, London, 1996.

${ }^{12}$ S. M. Richardson, Fluid Mechanics (Hemisphere Corporation, 1989).

${ }^{13}$ R. H. Perry and D. Green, Perry's Chemical Engineer's Handbook, 6th ed. (McGraw-Hill, New York, 1984).

${ }^{14}$ P. K. Bentley, S. S. Davis, O. L. Johnson, K. C. Lowe, and C. Washington, J. Pharm. Pharmacol. 41, 661 (1989).

${ }^{15}$ B. C. Boland and S. Whapham, "User Guide to Experimental Facilities at ISIS,'” Rutherford Appleton Laboratory, Report No. RAL 92-041 (1992); R. K. Heenan and S. M. King, in Proceedings of the International Seminar on Structural Investigations at Pulsed Neutron Sources, Dubna, Russia, September 1992, edited by V. L. Aksenov, A. M. Balagurov, and Yu. V. Taran (JINR, Dubna, 1993).

${ }^{16}$ J. L. Finney, Chem. Br. 27, 140 (1991); C. C. Wilson, Neutron News 1, 14 (1990); J. L. Finney, Europhys. News 20, 1 (1989).

${ }^{17}$ S. M. King and R. K. Heenan, in "Using COLETTE," Rutherford Appleton Laboratory Report No. RAL 95-005 (1995); R. K. Heenan, S. M. King, R. I. Osborn, and H. B. Stanley, "COLETTE Users Guide," Rutherford Appleton Laboratory Report No. RAL 89-128 (1989).

${ }^{18}$ G. D. Wignall and F. S. Bates, J. Appl. Crystallogr. 20, 28 (1987).

${ }^{19}$ P. G. Cummins, J. B. Hayter, J. Penfold, and E. Staples, Chem. Phys. Lett. 138, 436 (1987).

${ }^{20}$ S. M. King, V. M. Cloke, H. E. James, and C. Washington (unpublished).

${ }^{21}$ K. Schillén, W. Brown, and R. M. Johnsen, Macromolecules 27, 4825 (1994); K. Mortensen and J. S. Pedersen, ibid. 26, 805 (1993). 